\title{
NEOPLASIA IN HORSESHOE KIDNEY WITH PYELIC FUSION AND CROSSED SINGLE URETER
}

\author{
RENATO P. COSTA, CARLOS H. SCHAAL, FÁBIO C. NAVARRO \\ Section of Urology, Amaral Carvalho Hospital, Jau, São Paulo, Brazil
}

\begin{abstract}
Horseshoe kidney with pyelic fusion and crossed single ureter is a rare anomaly, with only 3 cases described in the literature. Such anomaly can be accompanied by other abnormalities, such as congenital scoliosis and situs inversus totalis. We present one case of this malformation associated with malignant neoplasia, treated with partial nephrectomy.
\end{abstract}

Key words: kidney; anomalies; kidney neoplasms

Int Braz J Urol. 2004; 30: 319-20

\section{INTRODUCTION}

Horseshoe kidney with pyelic fusion and crossed single ureter is a rare anomaly, with only 3 cases found in a research of literature through Medline. We present one case of this malformation associated with malignant neoplasia, treated with partial nephrectomy.

\section{CASE REPORT}

Female, 26-year old patient, complaining of colic on right lumbar region, underwent investigation by plain x-ray of abdomen that revealed no abnormality. An ultrasound of urinary tract was performed, showing a solid expansive lesion measuring $8 \times 4 \mathrm{~cm}$ in upper pole and middle portion of the right kidney, associated with horseshoe kidney. Abdominal computerized tomography (CT) (Figure-1) confirmed sonographic findings, demonstrating pyelic fusion associated with crossed single ureter as well.

No distant lesions were observed during staging. A cystoscopy was performed evidencing single ureteral meatus on the right side. Considering this condition, radical nephrectomy was indicated through bilateral subcostal incision, with partial nephrectomy being feasible, with cold ischemia during 30 minutes (Figure-2). No macroscopically involved lymph node was observed intraoperatively.

The pathological examination of the surgical specimen revealed clear cell carcinoma, Furhman nuclear grade I, measuring $8.3 \times 5.5 \times 4.5 \mathrm{~cm}$, weighting $200 \mathrm{~g}$, infiltrating the renal capsule, but with margins free of neoplasia. The pelvis and renal vein were not involved.

Patient has been followed for 8 months without any signs of recurrence.

\section{COMMENTS}

Horseshoe kidney with pyelic fusion and crossed single ureter is a rare anomaly, and to the moment we have not found reports in the literature concerning malignant neoplasia in association with such anomaly. The etiology of the malformation is unknown; however, some authors postulate that the ureter crosses the midline and divides itself in 2 halves, providing bilateral renal development (2). Associated extra-urinary anomalies have been described, such as situs inversus totalis and congenital 

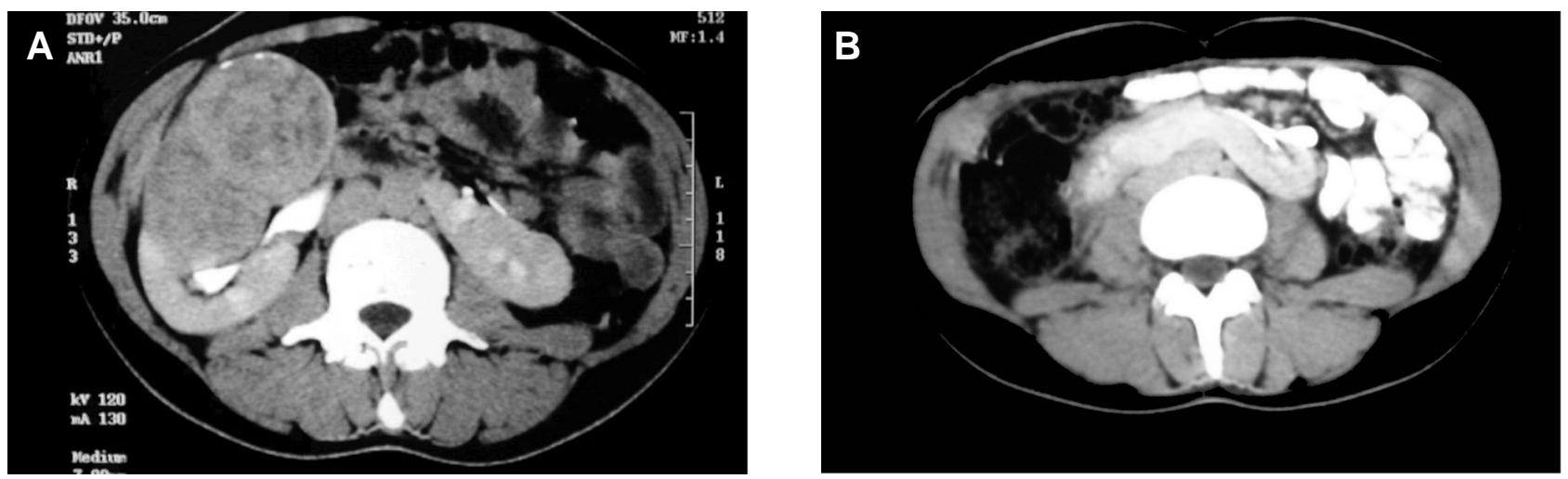

Figure 1 - A) Abdominal computerized tomography following oral and venous administration of contrast agents, demonstrating hypodense and heterogeneous lesion with peripheral enhancement in upper pole and middle portion of the right kidney $(8.3 \times 5.5 \times 4.5$ $\mathrm{cm}$ ). B) Abdominal computerized tomography with oral and venous administration of contrast agent, demonstrating pyelic fusion.
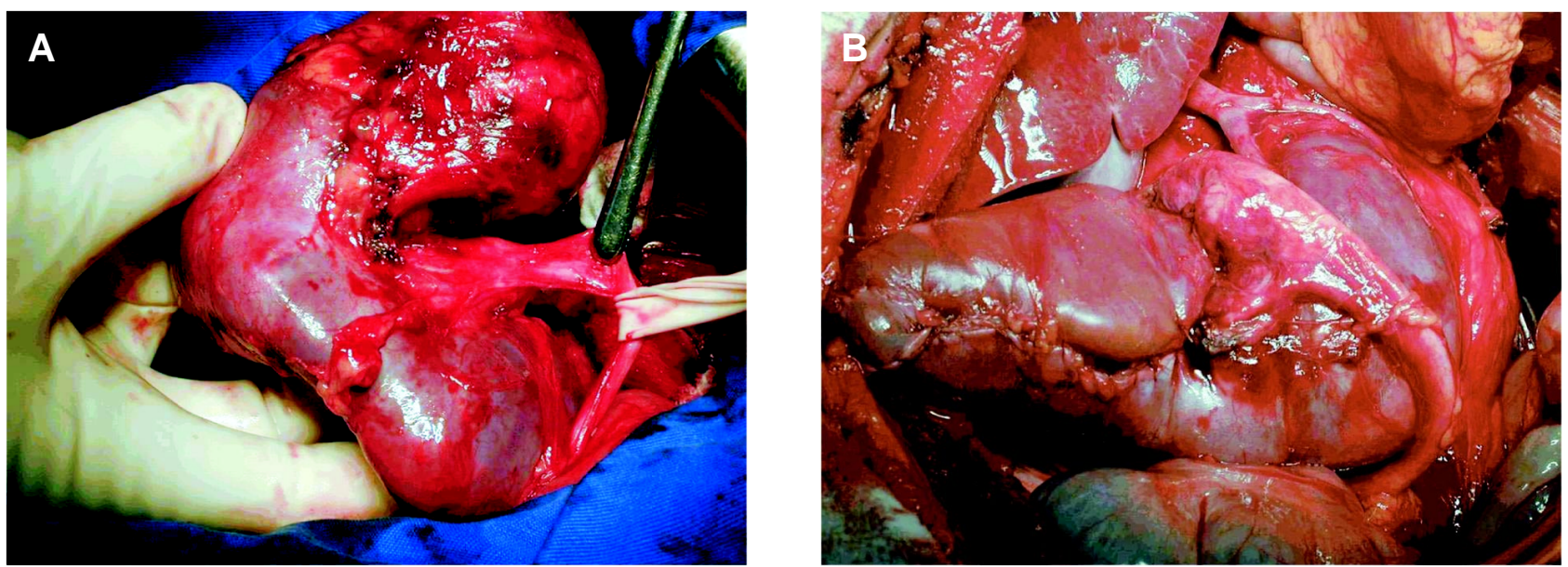

Figure 2 - A) Intraoperative aspect of horseshoe kidney with tumoral lesion in the upper pole of right kidney. B) Final surgical aspect, after right partial nephrectomy.

scoliosis $(2,3)$, however they were not observed in this case.

Even though the development of neoplasia in this malformation is rare, we believe that the outcome is probably similar to other malignant renal tumors. Surgical planning is fundamental for a successful treatment.

\section{REFERENCES}

1. Mungan NA, Gundogdu S, Erdem Z, Akduman B, Erdem O, Yesilli C: Horseshoe kidney with pyelic fusion and crossed single ureter. J Urol. 2003; 170: 1756.

2. Cass AS, Vitko RJ: Unusual variety of crossed renal ectopy renal with only one ureter. J Urol. 1972; 107: 1056-8.

3. Aragona F, Seretta V, Fiorentini L, Marconi A, Spinelli C: Combined renal and pyelic fusion with crossed ectopia of single ureter. Urology. 1986; 28: $339-41$.

Received: December 4, 2003 Accepted after revision: April 26, 2004

\section{Correspondence address:}

Dr. Renato Prado Costa

Rua Luiz Paiva, 100

Jaú, SP, 17210-090, Brazil

Fax: + 5514 3624-5155

E-mail: cehac@uol.com.br 